\title{
Revitalizing Small Historic Townscapes in Southern Province, Sri Lanka: Identifying Core-Elements Of Town's Identities Based On Residents' and Visitors' Cognition of Towns
}

\author{
Kapila Dharmasena Silva
}

\begin{abstract}
This research addresses the issues of preservation and revitalization of small-scale towns in the Southern Province in Sri Lanka. These towns were originated during the colonial occupation in the country in $18^{\text {th }}$ and $19^{\text {th }}$ centuries as service centers along main arteries that connected the main urban centers of the region. Although they currently do not have specific historical monuments, as grouping of buildings and as townscapes they possess specific identity by which one can distinguish them from the similar kind of towns in the other part of the country. However, the pressure for the growth and development has threatened this specific identity and the visual character of these towns. There is the need for the revitalization as well as preservation of these towns. Thus the major concern is how to struck the balance between the need for growth and change and the need for preservation and continuity. In this endeavor it is important to identify what components of these towns are to be preserved and what components are to be developed. The present study attempts to identify the core-characteristics of the physical settings to be preserved as well as to be developed in these towns. Hence, the final outcome of the project would be useful in two ways. First it will provide a basis to formulate a method that can be adopted in identifying the core elements of town's identity in preservation programs; second it will be useful in formulating a conceptual framework for the development and revitalization of these towns with a concern for preservation.
\end{abstract}

\section{Theoretical Framework}

\section{(1) Culture Change, Stress, and Preservation as a Coping Mechanism}

Historic preservation programs of towns are usually carried out to retain the cultural landscape of a community - mainly a certain built fabric, components or characteristics of the physical environment that represent the cultural identity of that particular community. However, the inevitable pressures for growth, development, and modernization result in a change of culture, and it could create a stressful situation that threatens the very identity, lifestyle and social cohesion of that community. In this context we can define development and modernization as 'culture change' while

preservation as an attempt to continue the culture and as a coping mechanism for culture change and its resultant stress (Silva:1999a:5-7). However, if the physical settings that are under preservation schemes are "living settings" - populated and active areas, and are not "dead" archaeological or museum sites - such preservation programs are inevitably forced to consider the issues of culture change. Preservation of the built fabric should retain and continue the identity of the people, but has to be compatible with the changing needs of the people as well. This is crucial to the success of the preservation activity. In such a context, design, development, and the preservation of the physical environment needs to be responsive to culture change and stress.

Stress due to change (and so, change of culture) results when there occurs a cognitive dissonance between the real impact of the change and the impact "perceived' by the people under the change. In coping with the stress and restoring balance or homeostasis in the stressed system, people should gain a sense of control over the change and also should be able to predict the change and its impact. If the change can be accurately predictable (or a familiar situation), a community would be able to take charge of it by adopting many mechanisms, such as accepting, adapting, moderating, modifying, withdrawing, avoiding, or resisting the change (Fig. 1). This reduces the probable gap between the real impact of the change and 'perceived/predicted' impact of it: hence the change will be less stressful (Rapoport:1978/ Silva:1999a:3-5). 


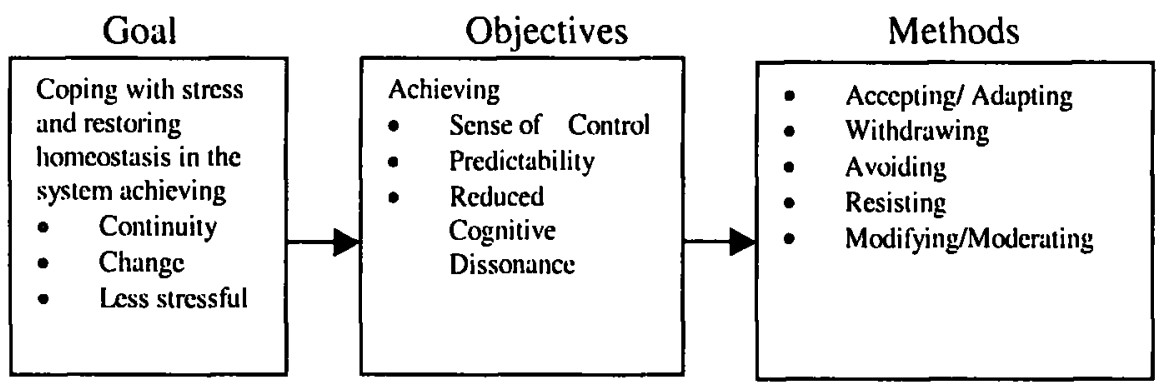

Fig.1.A Model of Stress Coping Responses

Within this framework we can consider preservation as a coping mechanism of culture change stress. Preservation attempts to continue what is familiar to the community, which results in dealing with the change either by resisting it, avoiding it or withdrawing from it. This familiarity also offers a sense of control over the change and hence the change is made predictable. Since it is inevitable, there must be a provision for change within the preserved aspects of a culture, including the cultural landscape. Thus total withdrawing or resisting the change will not bring the desired homeostasis in the culture. For a less stressful change, preservation need to resorts into accepting, adapting, and moderating the change.

Although historic preservation becomes critical in countering the culture change and stress resulted from ad hoc development and modernization activities, it can cause stress as well. First, preservation is usually a development control mechanism, and hence is perceived as hindrance to the growth and development of the environment, which can deprive the much-desired need to growth and develop the area, specially its physical improvements and economic potentials. This would again lead into a stressful situation among some groups of the community having controlled their freedom of choice, action and access to resources (Del Rio:1997:26). Second issue, related to the one above, is that although we preserve the buildings and townscapes, culture change continues - the aspirations and needs of the people would change over time - and the preserved environment would not be able to cater for this changing needs over time. This kind of inflexibility in the preservation programs once again creates stressed groups, and more over, becomes a threat/stress itself to the program. The nature of future change is usually unpredictable, hence it generates a perceived lack of control over a unpredictable impact. The next issue, related to the all of the above, is about the question that whose identities that we are trying to preserve and for whom. In the preservation activity, the decision-making comes from architects or planners; they decide what to preserve, what not to, and how to do it. Yet the largely forgotten component is the people who are going to live within these preserved environment. They have certain memories associated with the place, certain needs and aspirations, and certain lifestyle that gives them a sense of identity and self-worth. This again generates the sense of lack of control among the people as they do not know what is going to happen, what is to be expected, and hence such experience is stressful (Sell \& Zube: 1986:39). But it is less likely that a preservation program would consider all these different groups of the community. Thus, the most susceptible groups to stress of culture change may be totally out from the decision-making process of the preservation activity. Thus for them, such unknown future would be highly stressful.

Fourth, preservation activity may generate many other ill effects too. Preserved areas usually become tourist attractions, and there may be associated problems of parking, congestion, crowding, other socially unwarranted activities, competition with local people for existing facilities, and increase of prices of the facilities and goods, which may be unbearable to local community (Penfold: 1988:19, Sowa:1994:38). All these issues, if unattended, may be unacceptable and hence stressful to the local community. Fifth, in preservation, attention is given mainly to the preservation and improvement of the physical environment and hence it may tend to neglect the social and economic issues discussed above. There may be other issues related particularly to the culture, such as incongruities between the preserved areas - mainly its symbols and meanings that are preserved, reintroduced, newly introduced, or distorted - and the cultural value and norms systems. Some of the activities and physical features or symbols may not be in total fit with the way people used to perceive, and hence with the cognitive schema of the culture. Such situations can be stressful to many groups in the community, especially who are of more conservative about preservation and culture change. What to preserve, what to add or drop, how to make the environment more imageable, legible, meaningful, 
and hence culture-supportive, and how to identify these aspects are important issues in preservation activity. Sixth, these stressed groups may form defensive structuring which may either hinder preservation activities or demand certain conditions that may be hard to satisfy. These pressures on the program can come from both pro- and anti- preservation groups. Local authorities and governments will have many different requirements, that are different among them, and also, between them and local community groups.

All these issues can be very critical in the case of developing countries, where there are limitations of resources - financial, institutional, expertise, technology etc, unstable political and economic situations, rapid, abrupt, and ad hoc development and modernization efforts (Rapoport:1983:254/Sowa:1994:39-40/ Del Rio:1997:30-31/ Abu-Ghazzeh:1998:237-240). All of these aspects lead to unpredictable future and excessively intolerable culture change, which is stressful. In preservation programs, such uncertainties not only effect the failures in the program but also aggravate the above mentioned stresses inherent in the preservation activity. Thus problems of culture change and stress related to historic preservation in developing countries are more acute and need urgent and better solutions. The question here is how a preservation activity can be make more successful in terms of being a stress-coping mechanism that simultaneously support the continuity of the aspects of culture while allowing for desirable growth and development, i.e., culture change. In other words, preservation of historic urban districts needs to be culture-supportive: supportive for both continuity and change of the culture of a community.

\section{(2) Towards Culture-supportive Preservation}

Thus, culture-supportive preservation intends to achieve three results: first, maintaining continuity of the important aspects of the culture, which represents the identity of the community; second, facilitating culture change - a desirable level of growth and change in both physical and socio-economic environments; and third, by achieving the first two, making the preservation a less stressful development activity to the community. This can be further clarified based on our model of stress-coping mechanisms (Fig.1). Hence, the objectives behind this goal are to maintain a sense of control over both the control and promotion of growth in the environment, gaining predictability on these processes, and reducing any misfit between the perceived future generated by the preservation program and its real situation.

In to what kinds of methods should we resort in order to realize these objectives or what methods are available for culture-supportiveness in preservation? If we are to have both continuity and change of culture, it is imperative to know what is to be continued, what is to be changed, what change to be allowed, and how change is matched with the continued aspects of the culture. It is also important to know how one can identify those desirable aspects and levels to be continued and be allowed for change. In order to make the change less stressful, the rate of change should be moderated to a level that is manageable or controllable and predictable. To maximize the gains from such moderated rate of change further needs greater flexibility in preservation activity in terms of utilization and mobilization of resources, time to adapt and accept, policy considerations, and organizational support etc. The preservation activity should also consider all groups of society, their expectations, values etc in order to make the activity less stressful for all and to gain more flexibility as well. In other words, culture-supportive preservation includes understanding and maintaining what is to be preserved and changed, moderating the rate of change, maintaining flexibility, and involving all parties affected by preservation. We can summarize these objectives and these methods into the following model of culturesupportive preservation (Fig. 2).

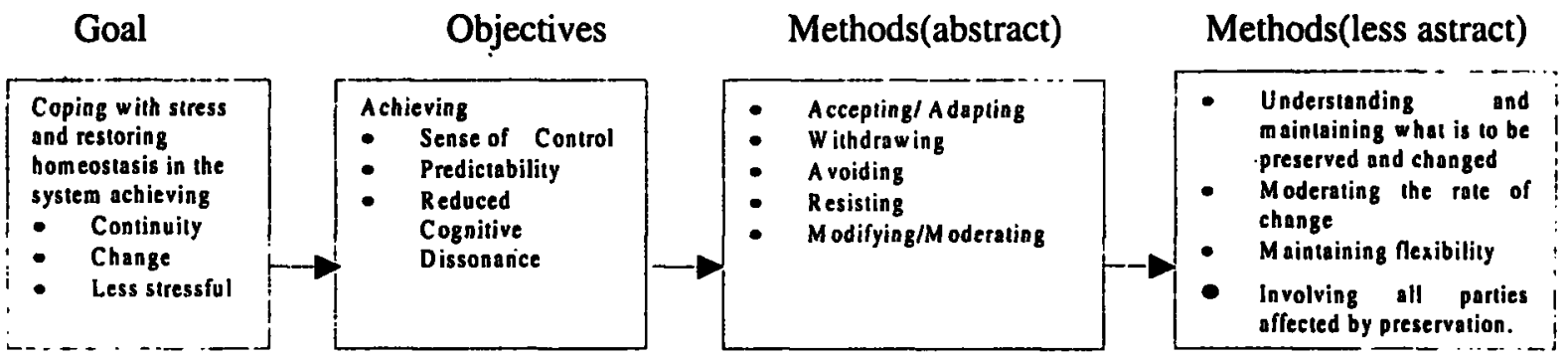

Fig.2. A Model of Culture-supportive Preservation 
These methods can be refined further. Rapoport (1983) proposes a specific conceptual framework for "culturesupportive design.' His method represents an approach to design, which emphasizes that socio-cultural variables are critical for the design of supportive environments. The underlying argument is that the culture of a community determines the behavior of its people, the nature of their built environment and the mechanisms that link behavior and the environment. Rapoport (1983:256-7) mentions that it is the central elements of the culture that are being supported. These could be called the elements of the culture core, those elements essential to the identity of the group, those less likely to change over time, and hence essential to the continuity of that culture. They may be specific attributes of the cultural landscape, various social groups, various types of social networks, value system, cognitive schemata, meanings, and lifestyles etc. There are peripheral elements to the culture as well. These are elements that are liable to rapid change and be replaced by new elements bring forth by the change - hence less important

(Fig.3).

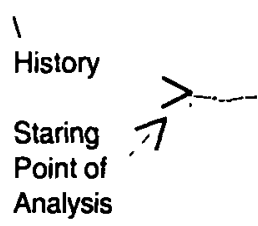

IElements changing little $\downarrow$ (Core Elements)
Elements changing much (Peripheral Elements)

\section{Fig.3. Culture Core and Periphery (Based on Rapoport: 1983:261}

Not only it is important to be able to distinguish between core and peripheral elements, one need to identify those elements of the environment by which the core cultural elements are being supported. There are important social units - castes, kin groups, families, social networks, etc, and the corresponding physical units, which vary in different scales - from dwellings to urban environments to regions - and in different systems of settings such as buildings, streets, open spaces etc. We need to identify the units of social integration or interaction for the group in question, by which the culture core is supported further. Also we need to identify the highly culture-specific institutions in which certain common economic, recreational, ritual, governing and other activities are carried out and taken care of. While these culture core elements are retained, the peripheral variables of the culture, which are less significant for the identity and lifestyle and are prone to change rapidly, are allowed to change. These changes to peripheral variables should be supported to generate new faces and characteristics desired for the change occurred in the socio-physical environment, which will create a familiarity of the change and hence, reduced stress. Further these peripheral changes should be in congruence with the retained core elements of culture.

However, both these retained culture core and new aspects of the peripheral variables need synthesis, in order to become a unified culture for the future of the community. Thus, we need to identify the mechanisms of synthesis of the core cultural system and the attributes of modern change: in other words, how the culture and the change as well are being supported. In this synthesis, one finds that the changed environment has a reduced set of characteristics congruent with the core culture, and new characteristics coming in, both in the environment and culture. Thus mechanisms of incorporating elements, replacing certain elements, generating new versions of old elements, revising new elements, isolation of old elements, or even reappearing of certain elements given up some time back in history etc, can be seen. (Fig. 4). 


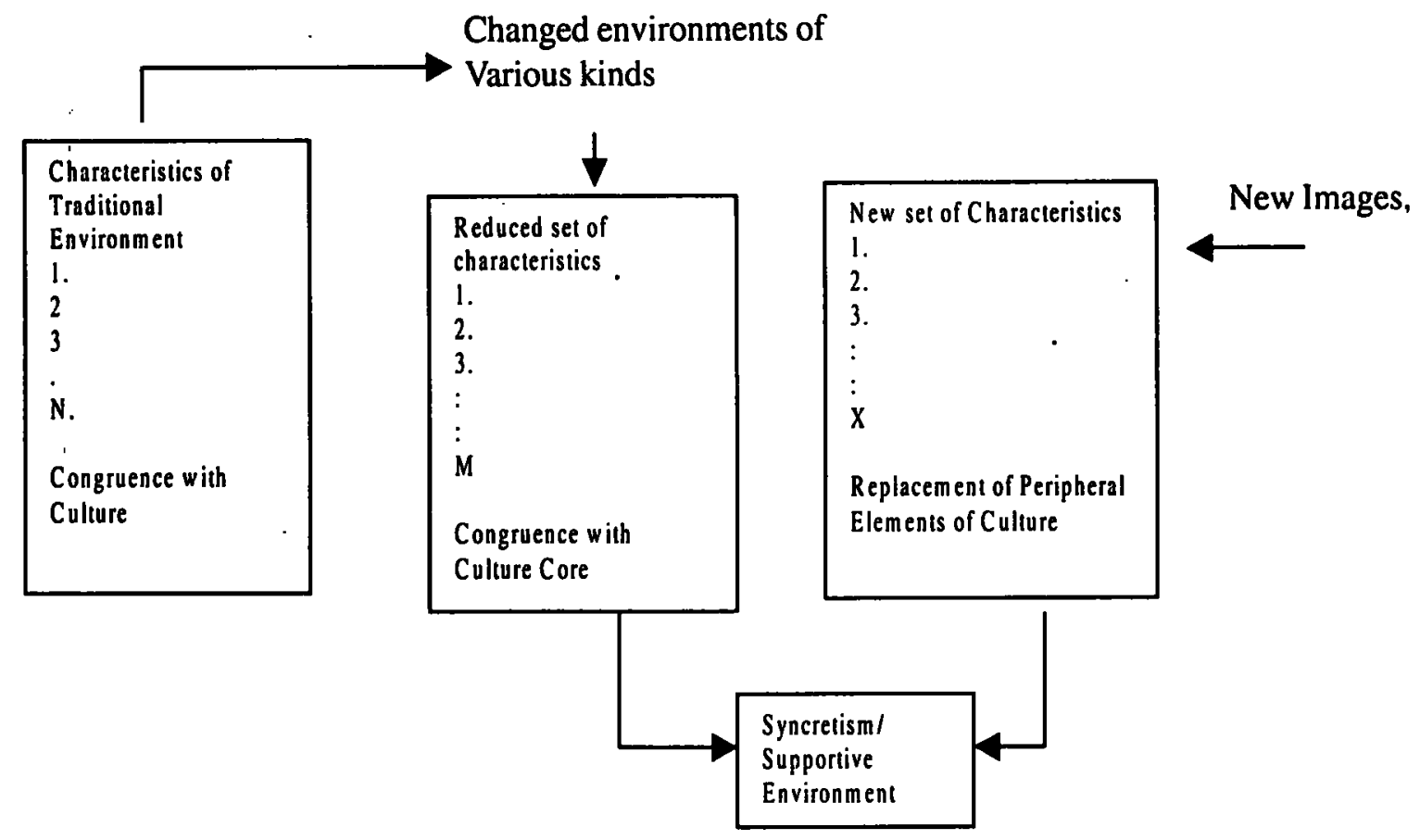

Fig.4. The synthesis of culture core and change (Based on Rapoport:1983:261).

Rapoport's conceptual framework for culturesupportive design is complimentary to the proposed model for culture-supportive preservation (given in Fig.2) The task of the culture-supportive design, development or preservation is thus to achieve this balance and syncretism in the environment - both sociocultural and physical. Culture-supportive preservation does not propose to stop change; rather it modulates the nature and rate of change. This modulation of rate of change facilitates first to understand the core (what is to be preserved) and peripheral (what is to be changed/grown) of the culture. Then it facilitates moderation and modification of the nature of change modifying the changing peripheral aspects to be in congruence with core elements, and hence, facilitates better syncretism of core and changing aspects of culture. This process requires flexibility either to accept, adapt to that or to find out better solutions to resist the change or to rectify any incorrect syncretism. Flexibility calls for gradual and incremental change, eventual syncretism, and allows having a control over the development activity, and thus makes it less stressful. Getting all parties concerned involved in the preservation activity facilitates to understand the core elements of their culture, their changing value systems, less important aspects of their culture, and better means of syncretism etc. Such participation also allows these groups having a sense of control over the preservation activity, reduces any misfits between their perception of the impact of the preservation and its real impact, and encourages desirable adaptation and acceptance rather than forcing them to withdraw or resist the preservation activity.

\section{(3) Core-Elements of the Cultural Landscape and the Notion of Cognitive Image}

The next question is how we identify the core \& peripheral elements of the cultural space as identified by its community. It has been identified that people create a "subjective space" in their minds based on their perceptual experience of the outside environment, and their behavior and expectations within the objective environment is largely governed by this "subjective or cognitive image of the objective space." People select the environmental information perceived and then encode, modify, store, retrieve, and decode them by cognitive processes of the brain for desired behavior within the environment. In this process they form a 'cognitive representation' or a mental model of the environment. By forming this cognitive image, people make their environment meaningful by understanding, structuring it, learning it, and relating themselves to such an ordered milieu. (Silva:1999b:10-12). Lynch (1960:89) mentions that a cognitive image is constituted of three components: identity, structure, and meaning. A workable cognitive image requires first the identification of an object, which implies its distinction from other things, its recognition as a separable entity. The cognitive image must then include the spatial or pattern relation of the object to the observer and to other objects, which 
is called structure. Finally, this object must have some meaning for the observer, whether practical or emotional. Meaning also is a relation, but quite different from spatial or pattern relation. An object or an urban setting is highly imageable if it can facilitate the making of vividly identified, powerfully structured, highly meaningful cognitive image of it. A cognitive image held by an individual is not directly observable, as it is an internal, mental construct. Yet it can be "externalize" by some other observable means that stands for or symbolize it. For example, a painting representing a landscape, a sketched map representing cognitive map of a place, or a poem or a novel or a verbal comment describing the landscape etc can be external forms of representing the cognitive image of that environment (Silva:1999b:13).

Thus any change occurs in the objective cultural space creates a cognitive dissonance between the objective change and the cognitive image of the space held by the community, resulting a stressful situation. Accordingly, in culture-supportive preservation, it is imperative to understand how a community cognize their cultural space and what constitutes the core-elements in their cognitive image of the objective cultural space.

However, different individuals would have different cognitive images of the same setting based on their

individual differences such as age, sex, education, their familiarity of the setting, and the nature of their affective attachment to the setting. Lynch (1960) mentions that individuals of a specific community would have a "consensual image" - a shared image of their cultural landscape, which is comprised of key elements commonly important to all of that community - with minor distortions based on individual differences. Thus, another outside community would have a quite different shared image of this particular landscape, as their level of interaction with it and their cognitive styles (based on sub-culture) could be very different from the resident community. Therefore, outsiders (visitors) of a specific setting would have a different image of it than its insiders (residents).

Accordingly, visitors to a specific cultural landscape would identify a set of core-elements different to what would the residents of that setting would consider as core-elements of their setting. However, in preservation, the cultural space must be able to communicate the same message about its core-elements to both residents and visitors equally. Accordingly, in identifying coreelements to be preserved of a specific setting. it requires to study what both residents and visitors think of the core-elements of the identity of that cultural landscape. Thus we can finally propose our theoretical framework as in figure 5 .

\section{Methods(abstract)}

\section{Methods}

(specific)

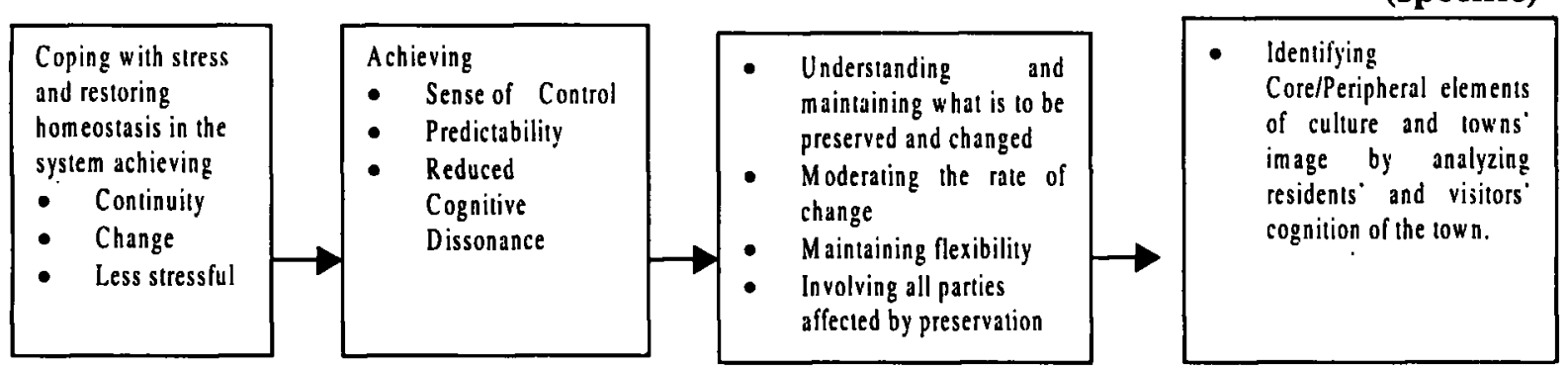

Fig.5. A Model of Culture-supportive Preservation

\section{The Setting and Selected Towns}

The setting of the study is the small towns dispersed over Galle and Matara districts of the southern province (Fig.6). The origin of these towns goes back to the period of colonial domination of the southern and maritime provinces of the country in the $18^{\text {th }}$ and $19^{\text {th }}$ centuries. They originated as service centers along main arterial roads that connected the main urban centers of the southern province with the capital city of Colombo in the western province of the country.
During the colonial period, most of these small towns served as either trading places or seaports for this cinnamon, tea, rubber and other crop cultivation. Economic and social life of some of these towns is still centered on these activities. The change occurred within these small towns are much slower compared to other parts of the country and hence retain much of their original form and the character. However, they are now faced with the increased pressure for growth and change, and hence needs preservation efforts to retain their identity while achieving the desired growth. 
In a survey carried out in this region ${ }^{1}$, three different categories of towns were identified based on their scale, character, and the urban form. The first category is called "Urban Nodes" as these places are on the intersections of main roads and yet have not developed into a scale to be called as towns. These nodes are comprised of shops and a market place and serve a population of 2000-5000. These nodes possess a strong visual character and identity and represent the genesis of the urban form of the towns in the southern province. The next category is "Linear Towns" as they are ribbon developments along the main arteries. They serve a population of $10,000-30,000$ people and contain many different commercial and other urban activities. Almost all of these towns still have its original core or the "urban node" intact. The last category is "Linear Systems" which is a spreader development of the linear towns that serve $30,000-50,000$ people. However, all these categories of towns shared a similar activity patterns, visual characters, and physical features. Thirty of urban nodes, 15 of linear towns and 05 of linear system towns are identified. For the purpose of this study, 03 examples of each category were selected for a detailed analysis of the core elements of the visual character and ambience. The selection was based on the complexity of activities that these towns have and the clarity of their character. Accordingly the following towns have been selected for the study (Fig.6):

\section{Urban Nodes: Denipitiya, Walsgala, and Wanduramba \\ Linear Towns: Akuressa, Imaduwa, and \\ Kurundugaha-Hetekma \\ Linear Systems : Ambalangoda, Devinuvara, and Weligama}

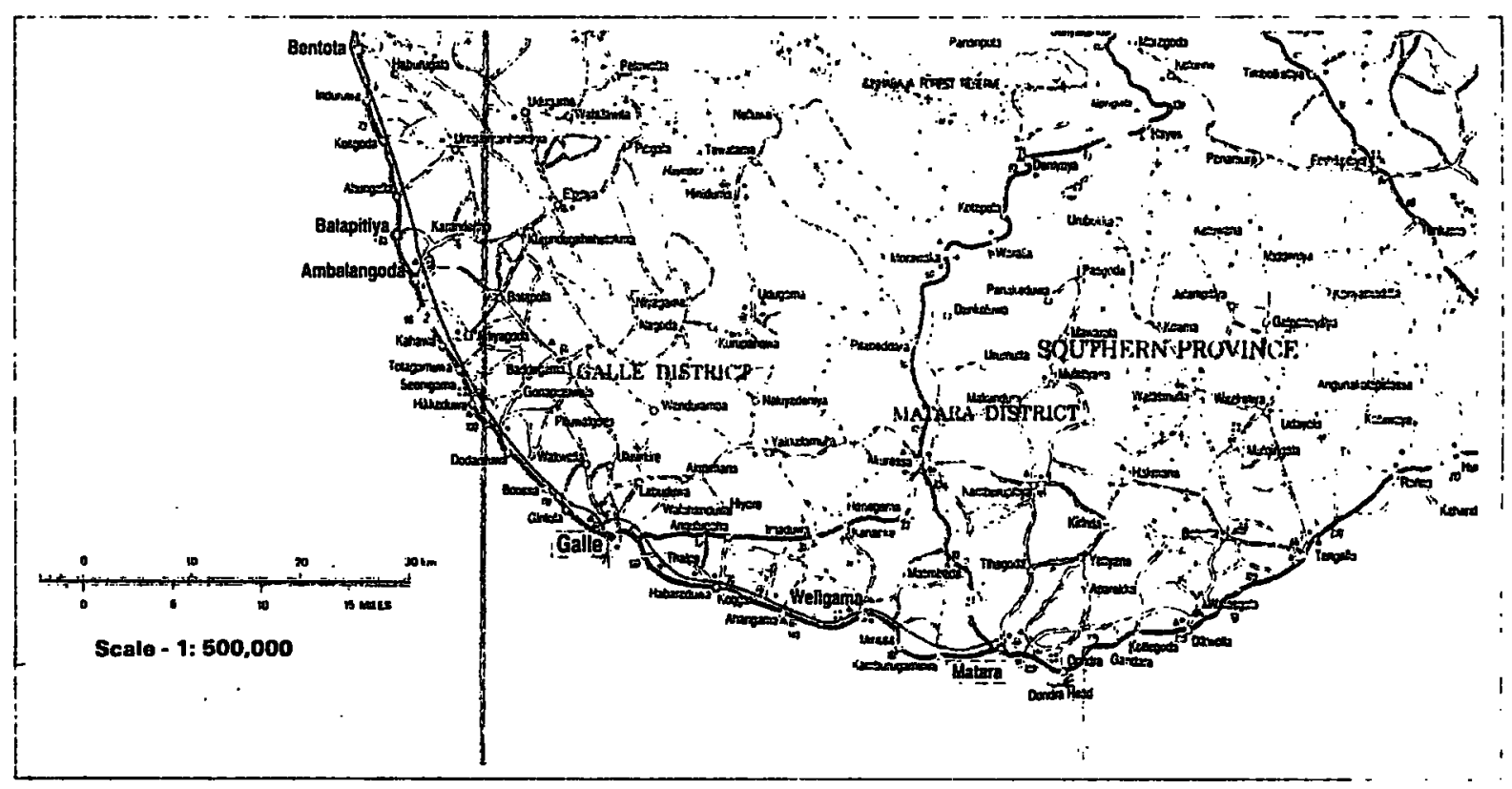

Fig.6 A Part Map of the Southern Province, Sri Lanka

The urban node of Denipitiya is situated $2 \mathrm{~km}$ off Weligama-Akuressa road to the just north of Weligama town. Even in the late $18^{\text {th }}$ century, Denipitiya was known for its Market as wholesale trades center for vegetables, and for the gigantic Banyan tree that stretched over the Polwathuoya River that runs in the vicinity of the node. Although the historic tree is no more, a root-branch of it still survives on the southern bank of the river. The node's economic and social life is still based on this wholesale farmers' market which is held for three days per week. The whole node becomes alive during these days and almost deserted during the rest of the week. The Walasgala urban node is located $35 \mathrm{~km}$ east of Matara Town on the old MataraBeliatta road. In early $19^{\text {th }}$ century, a local chieftain had donated parts of the land of this forest cover to build up a temple. Since there was a cave in this land, inhabited by bears, the temple became to be called Walasgala Temple. The urban node later grawn around the temple (originally as a temporary setting during

1. This survey was carried out in 1997 \& 1998 by the author and a student of the Department of Architecture,

University of Moratuwa. For details see Senanayake: 1997 
the temple festive seasons) was also called Walasgala. The whole Walasgala node is centered around a daily and busy Farmers' market, which is the wholesale trades center for 18 villages surrounding Walasgala village. The node has remained unchanged and undeveloped for many decades. Wanduramba urban node is located $20 \mathrm{~km}$ north-east of Galle off the GalleBaddegama road. It is a node connecting four towns Galle, Baddegama, Yakkalamulla and Udugama - and literally a junction having four roads branching off towards these towns bearing the names of the towns respectively. The social-economic life of Wanduramba is woven around the farmers' market that serves many surrounding villages.

Akuressa Town is located $25 \mathrm{~km}$ north of Matara and $35 \mathrm{~km}$ northeast of Galle on the Matara-Deniyaya main artery, which runs parallel to the Nilvala River. The town originated as a commercial center for crop cultivation with farmers' market and later in $18^{\text {th }}$ century became a garrison town for the Dutch who occupied the southern province of the island. The town began to grow along the main road and developed into a linear town and became an important trading center for low-country tea, rubber, \& cinnamon cultivation during the late $19^{\text {th }}$ century. However, there are no remains of the fortress built by Dutch today, and it is hard to trace where it was or how it affected the development of the town. Two new by-pass roads are being constructed to manage the traffic flow through the town and this may eventually change the town's character as a linear development. Imaduwa Town is located $20 \mathrm{~km}$ east of Galle on the Galle-Akuressa Road. The origin of the town relates to it being an intersection that connects four towns in the region Galle, Akuressa, Ahangama, and Yakkalamulla. The present name of the town is a distorted version of the earlier name, which referred to a bamboo forest in the area. The area has been known for tea, rubber, and paddy cultivation form the $19^{\text {th }}$ century, which resulted in establishing farmers' market for crops and a rest house for the British and local proprietors who dealt with tea plantations. The rest house buildings were later converted into a hospital. The Galle-Akuressa road is boarded by a mountain range and it restricts the spread of the town only along the road. The KurundugahaHethekma Town is located about $12 \mathrm{~km}$ east to Ambalangoda along the Ambalangoda-Elpitiya Road. The town has been centered on the cinnamon trade from the $18^{\text {th }}$ century. The name of the town itself is reminiscent of this past and the present life of the town. The town was also considered important in paddy cultivation in 1950s to 1970s, and there still are granaries built by the governments of that era, which are now underutilized.

The town of Ambalangoda is situated on the main coastal highway connecting the cities of Colombo and Galle, and is $85 \mathrm{~km}$ away from Colombo. It is the last major town before one reaches Galle, and historically considered a transit palace or a place where one needs to pause a while or to spend a night during the journey to Galle. The name "Ambalangoda" means a place full of Ambalamas - the traditional wayside-resting place. Most of these Ambalamas were replaced by a Rest House built by the British administration during their domination over the southern region. The town's written history can be traced back to early $15^{\text {th }}$ century. The town's economic life is still based on cinnamon trade and fisheries industry and it is a major service center catering for commercial, educational, cultural needs of the villages and small urban centers around. The town is well-known for its crafts and arts industry, especially masks industry, puppet dancing, and special form of traditional dancing called Ruhunu dancing. The old lown was developed along the Galle road, and in mid 1920s, a new road was constructed by-passing the old Galle Road on the land side, thus creating an urban sprawl along this new road as well. Although much of the town's life has been now transferred to the new Galle road, these two roads and the domains on either side of the roads and in-between constitute the town. The town of Devinuvara is situated along the highways connecting Matara to the Tangalle town, and is $165 \mathrm{~km}$ further down from Colombo. Devinuvara town has a history that dates back to $3^{\text {rd }}$ century BC and started as a "Devalagama" - a village dedicated to a temple and a shrine of a deity. The shrine in Devinuvara is dedicated to the God Vishnu - one of Triad of Great Gods of Hinduism, and is the main shrine of God Vishnu in the country. Usually a Devalagama has a specific layout: The main shrine complex is connected to a small shrine called "Simhasana" where the jewelry and the weapons of the God is deposited during the annual festivals of the shrine - by an axial street. This street is used for the processions and ceremonies during the annual festival season. The lands on either side of the street are given to the people who serve the temple and the shrine. Appropriately, the term 'Devinuvara" means the "city of god'. The town developed and evolved from this earlier version of Devalagama and still retains some of its characteristics. The town of Weligama is situated along the main coastal highway connecting Colombo and Matara cities, via Galle, and is $145 \mathrm{~km}$ away from Colombo. The history of Weligama dates back to the 
sculpture of the Bodhisattva Avalokithesvara carved out on a rock boulder, which dates back to $7^{\text {th }}$ century AD. Historically Weligama was a seaport and a thriving center of spice trade, jewelry, and other commercial activities. Historical accounts mention the busy life and the shops in Weligama town. Traders who came from Arab countries were mainly involved in the trading activities and still there is a predominant Muslim population in Weligama town. Although there is no seaport today, Weligama has a fisheries harbor and is still active in the cinnamon trade. In early 1960 s a new road was constructed bypassing the old road between Matara and Galle and the core of the town. Thus the most of the activities were shifted towards the new road and especially around the new bus station. The old core of the town was centered on the railway station and the jewelry and cinnamon shops.

\section{Research Questions and the Methodology}

Based on the above approach, this research addresses a specific issue in the development and revitalization of small towns in the southern province in Sri Lanka the issue of conserving and maintaining the identities of these towns. Hence, the main purpose of the study is to identify the core characteristics that are central to the identity and character of the small towns in the southern province in Sri Lanka as identified both by the residents and visitors of these towns. The study assumes that the identity of the town is constituted by the physical character generated from the urban form and by the ambience created by the activities of the town. It further assumes that natives or residents of these towns hold a shared cognitive image of the town and that this shared image can be correlated to a shared image of the town held by newcomers or outside visitors. It also assumes that links can be seen between these shared images and particular characteristics of the urban form and town's activities. Based on these assumptions, the study attempted to answer the following sub-questions:

1. According to the residents of the towns, what constitutes the important characteristics of towns' identities?

2. According to the visitors to the towns, what constitutes the important characteristics of towns' identities?

3. Can we identify a set of core-characteristics that are central to the identity, character and ambience of all these towns from triangulating shared cognitive images of residents and visitors of these towns? $3^{\text {rl }}$ century BC. It is believed that a sapling of the sacred Bodhi Tree. under which the Buddha attained enlightenment was planted in a temple near the Weligama town and is believed to be still there. Near this temple, there is a In order to answer the research questions, two types of data were collected: Cognitive maps of the towns and verbal comments on the towns' physical characteristics and development potentials. These data were supposed to provide a comprehensive understanding of the core elements of characters of these towns from the points of views of residents (people of these towns) and visitors (newcomers or outsiders to these towns). Twenty people from each town were randomly selected and asked to draw a cognitive map of the town. Also, 20 first year students of the Architecture Department at the University of Moratuwa - Sri Lanka, who have never been to these towns, were selected and taken into these towns, and then asked to draw cognitive maps of towns. These participants - both residents of the towns and visitors - were interviewed further to clarify what they think as central to the character and to the identity of the town. These interviews took unstructured form yet attempted to get peoples' comments on the kind of change, growth or the improvements that these towns require and how they think such development can be carried out. These data were supplementary to the cognitive maps collected and hence qualified the data. It is assumed that they also reflected the peoples' needs and aspirations about the change and growth of the town and its life.

The data analysis was carried out simultaneously with data collection as to refine the data collection methods. However, the main data analysis process was comprised on three phases. Under the first phase, the cognitive maps collected from residents of each town and from visitors to those towns were analyzed separately to identify the specific elements and patterns that both types of participants considered as important to the town's identity. Then those findings were triangulated to identify common elements and patterns that are central to each town's identity. The verbal comments of both types of participants were also used here to further support the analysis. This analysis of cognitive maps data were based on the cognitive mapanalyzing framework presented below. In the second phase, common cognitive elements identified for each individual town were compared to see whether there are any commonalties of cognitive elements among these towns. In the third phase, all these findings (derived separately from each data category) were compared and triangulated to identify the specific core elements of character and identity common to all towns. 
Research Questions Data Cognitive Maps Analysis Framework \& Findings

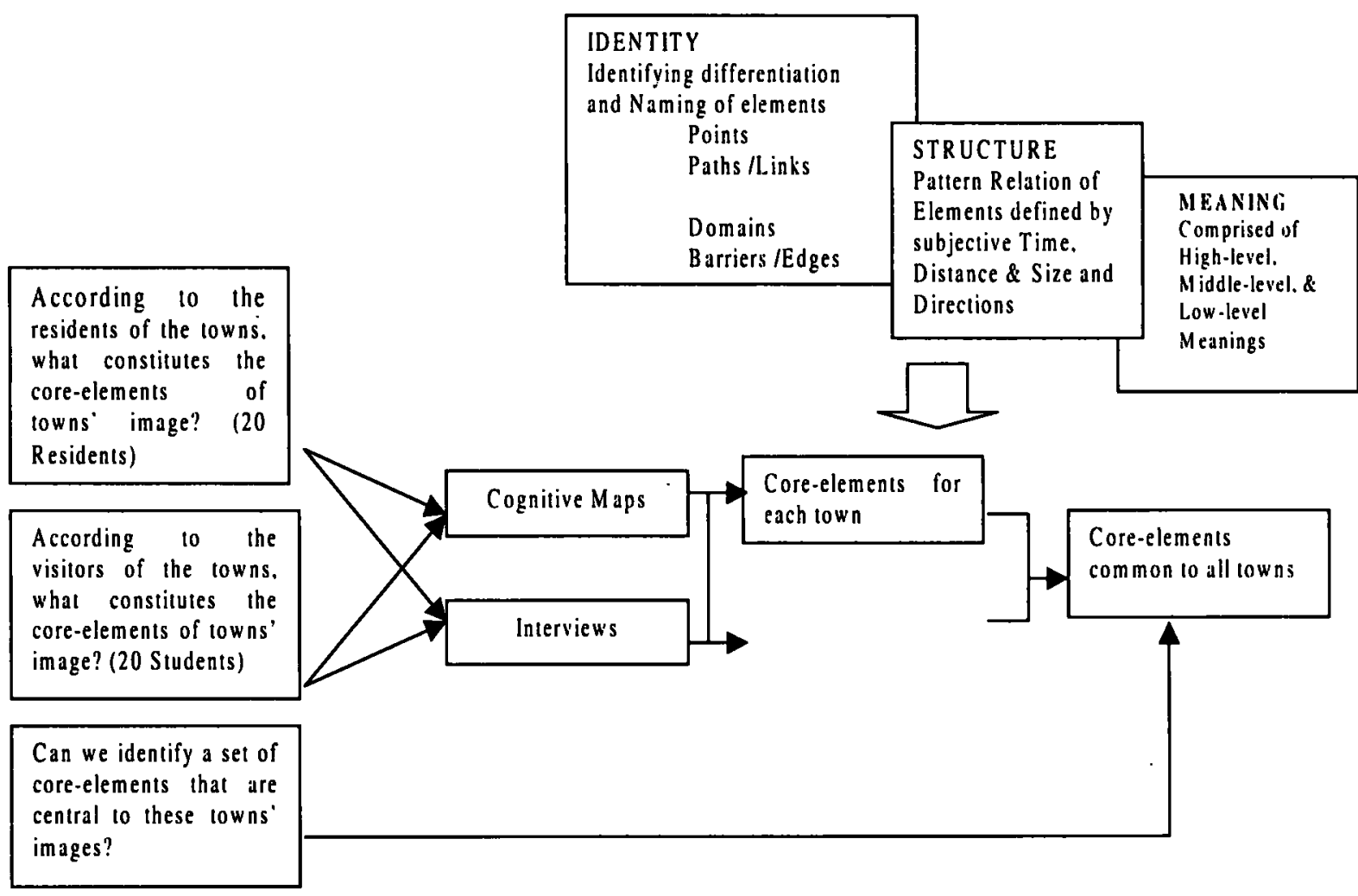

Fig.7. Research Questions and Methodology of the Study

\section{Data and Findings}

For both residents and visitors to Denipitiya, the farmers' market, bridge, Banyan tree, Neegrodarama Temple, and the post office formed the top order level points of their cognition. The junction itself and the four roads are important as links. The Polwathuoya River was also an important edge in their mental image of the node. Both parties conceptualized the whole node as a one domain, and the outer domains such as coconut cultivation and vegetable gardens were also important for their cognition. Memory of the Banyan tree and the significance of the market for the socio-economic life of the town and the ambience created by the busy activities in the center were central to the image. However, for the residents, the Welihinda Temple, Neegrodarama Temple, and other surrounding religious settings were very meaningful places for their mental concept of Denipitiya village and its urban node. In Walasgala, both residents and visitors tend to share a common image, which is constituted by conceiving the node as a single domain clearly demarcated by the shops (as edges or linear sub-domains), which is centered around the powerful presence of the Bo tree. The farmers' market is the hub of the town's life and hence was considered important to the imageability of the lown. Other than these, the temple, bank office, gas station, post office, and medical center were held significant for the town's identity. Matara-Beliatta Road acted as a spine to which other lower order points were linked. In Wanduramba, the bus station, Bo tree shrine, the college, and the farmers' market were the most significant core-elements (whether they are considered domains or points) of the node including the four roads. The close location of the Wanduramba Temple and the Galapatha Temple was also important to generate a sense of meaning to the place. Post office and the provincial council library were also important for the residents. The image of the junction area that includes the bus station, Bo tree shrine, college, and shops around was most important for both residents and visitors to create a memorable picture of the town.

For both residents and visitors, the main street acted as a spine that organizes the structure and other elements of Akuressa Town. The bus station, the police station, the bridge, and the market were the most vital points of the town. Bank offices, Amalagoda Junction, Godapitiya Temple, post office, and the hospital can be considered other core-points of the town. However, 
the bus station and the market and their surroundings could also be conceptualized as domains. Although the river acts as an edge, Tibbotuwawa node became a core-domain of the town's structure. The Kamburupitya Road, Bangama Road and the new road became other significant paths of the town. The Godapitiya Temple and the Bo-tree shrine can be identified as important places in the town. The image of the bus station as a center and the image of bridge were also significant aspects that contribute to a strong imageability of the town. In Imaduwa, all four roads should be regarded vital to the town's identity. The bus station, the Paragoda temple, gas station, the Central College and its primary school, bank offices, hospital, post office, and the market can be considered the key-points and domains of the town's identity. Image of the Imaduwa Junction including the shops around would be important to the strong imageability of the town. The Pagoda Temple, legends related to the town's name and origin, and the cultivation activities would still be important aspects that would generate some meanings to the residents of Imaduwa Town. Both participant groups consider the main street of the Kurundugaha-Hethekma town as a spine. The other paths - Batapola Road, Ella Road, and Talawa Road have also been shared as important. The temple, church, clock tower, convent, the elderly home, granaries and the playground were the core-points in the town. The area surrounding the clock tower alșo was seen as a domain due to its spatial order. The temple, cinnamon trade, and the legends of the town's name generated meanings about the town and its history. Other than that the domain around clock tower, the convent, and the elderly home would be imageable places as well.

If Ambalangoda, it seems that the two Galle Roads and the two connecting streets - the Station Road and the Wickramasuriya Road were important to the town's identity. The next order paths would then include the Beach road and the Elpitiya road. The Beach and the fishermen's villages became distinctive domains as commonly conceptualized by both participant groups. The core-points of the town included the bus station, railway station, two entry points (roundabout and the bridge), the Temple, the Hindu Shrine, two schools, the mask museum, the Rest House, farmers' market, and the town council hall. Memorable experiences of the town were generated largely by the busy activity center around the bus station and the entering experience to the town from both Galle and Colombo directions. The town's main cultural industry - Masks and Puppet arts and the Rest House and its history would be central to the identity of the town as well. A comparison of visitors' and residents' cognitive maps of Devinuvara indicates that the main shrine complex is the core and the most vital element of the town. The all five roads were identified as necessary to the path-structure of the town. The Simhasana, Lighthouse, Banyan tree, Clock Tower, Market and the ruins of "Gal-ge" were the important points in the town. The sea, beach, and fishermen's villages were the other important domains of the town. The town of Devinuvara would continue to generate strong mental images in both groups due to its religious significance, it being the southern-most tip of the island, and due to the significance of the historic Lighthouse. The Banyan tree and the ruins of the "Gal-ge" also add meanings to the mental images of the town held by people. Although both parties did not identify the historic layout of the town, it should be considered an essential part of the town's identity, as it establishes a pattern relationship of the elements with an underlying higher-order meaning. In Weligama, the residents held Agrabodhi Vihara and the Kustharajagala important for the town's identity, although visitors did not refer to them. These two places along with the island in the sea, the bus station, police station, the railway station, the old mosque, the post office, and the pottery display in Kumbalgama constituted the image of the town. The two Matara roads, two Station roads, the Hetti Veediya, and the Akuressa road can be identified as the core-streets of the town. The bus station area, the beach, and the Kumbalgama area would be strong image-evokers of the Weligama town. The bus station and its surroundings were perceived as the center of the town.

\section{Shared Core- Charchteristics of Towns' Identities}

From the above data and findings, we can derive a set of common core-characteristics of identities of towns, as shared both by visitors and residents, in the southern province, Sri Lanka. We also can identify some notions related to the preservation and development of these towns based on these findings. However, the discussion should not be taken as conclusive in itself or as a recipe to be applied directly into the development and preservation programs. They only indicate the important issues that most planners, architects, and preservationists would overlook or take for granted, and hence emphasizes the need for more research in identifying the means of making the development efforts more meaningful and acceptable to people both outside and inside of these towns. 
It seems that residents in these towns tend to structure the urban environment, as a general rule, into a pathpoint structure and to consider the town as consisting of two domains - commercial center of the town as the 'town proper' and the rest (the residential areas) as the 'village'. However, based on visitors' cognition, we can conclude that both outsiders and insiders consider the towns as a combination of points, paths, and domains. The important points they identify are the entry points to the towns and the main bus station as the center or the core of the town. People prefer to see any intense commercial activities and gatherings to be placed around this core or to have clear links from those places to the central core. The center seems to be a spacious area rather than being a congested place; a gathering place and also a point that connects the town to the other areas of the country via the transport modes - where one symbolically arrives in the town or leaves it. The other activity center is the market - as a main shopping complex or as farmers' markets as much of the socio-economic life of these towns is woven around them. The railway station (if there is any), the governmental institutional buildings (or activities) such as the police station and post office are also significant points for the life and hence to the imageability of these towns. Thus, their visual and physical accessibility and location in relation to the cores of the town are also vital factors that affect imageability. Places of historical and religious importance always need some attention and incorporation with the development activities. Where these places play a central role (both spatially and activity wise), they always evoked a strong image in people's minds. Especially Bo-trees (with or without shrine structures) and other large trees such as Banyan Trees become highly imageable elements in towns, due to their physical prominence, symbolic content, and specially when they are located at towns' centers (market, bus station, main junctions, and at towns' original cores).

People also tend to consider streets as significant domains where the life of the town manifest, rather than as mere transport routes: what is behind the street wall is "rural" or insignificant to the town's life and what occurs in the street is "urban". This may also be due to the fact that most of the small towns in the country are linear towns or ribbon developments along the main highways. There always is a main street, even though the setting is a linear system or a node, which acts as a spine of the town's structure. This main pathway may be the actual major street of the town, or may be the one that connects the next two important towns to the place in question or along which the main commercial activities are located. Other than this main pathway, people usually identify the all the other pathways branching off from the main path, and leading to other towns or villages or places of historic/religious significance. They also identify the major connection routes between the centers of the town.

Residents usually did not refer to the sea or the beach and to the plantation estates around the towns, although they are very significant domains for the towns' identities. This is proved as visitors frequently refer to these places. The reason why residents neglect to mention these contextual aspects is not clear. Perhaps they considered the commercially active, dense area as the town and regarded what is outside as village or irrelevant to the notion of "town". Although residents did not mention these domains in their cognitive maps, they used to talk about them - the importance of the tow $n$ in its region and its plantation and trading activities, and these references showed clearly that these significant contextual aspects evoke strong images about the towns in residents' minds. These aspects were more meaningful to the residents than visitors, who just referred to what they visually perceive as noticeable features of towns' contexts. Thus, the identification of "town" and "village" as two domains, the sea, beach, estates, market, and sometimes the bus station as domains seems a common cognitive notion to the people. Usually what people identified as the center of the town should be a domain, by definition, and the bus station should thus include the surrounding shops, trees etc as well. This may be the reason that most people referred to the bus stations as more imageable places.

People made some individual references various points in towns, such as specific shops and locations in and around towns. As these places did not get a high a common mandate, these places can not be considered core-elements of towns: rather they can be identified as the peripheral aspects of towns' identities, and hence, can be changed or developed. These places may also vary from town to town, and thus do not pose any significance to a common or shared identity of all the towns concerned. Perhaps, some of these locations may be important to a particular town's identity, but this should be decided separately when dealing with the identity of that specific town.

\section{Issues of Preserving Towns' Identities}

Accordingly the preservation (or development) activities in these towns need to consider these factors as the core-characteristics that should be preserved, developed or maintained. It appears that towns with clearly marked entry points and the busy center of town holding a bus station, market, and other main 
commercial activities, may be a suitable urban form for small towns in the southern province, Sri Lanka. In the case of urban nodes, the whole node should be considered as single domain, centered on the market place rather than the bus station. The node would include the market, any large trees around (if any), the bus stops placed at either ends of the node (entry/exit) or the bus station (if any), and the shops acting as edges and providing a strong sense of enclosure to the setting. Any such shop buildings should be preserved in terms of scale, degree of enclosure, and other noticeable historic/architectural features. Both Walasgala and Denipitiya do not have a central bus station, but the whole life of the place is based on the farmers' markets, which are suitably located at the center of the node. In Denipitiya, the preservation of the Banyan Tree, Neegrodharama Temple, and Welihinda Temple is very important to maintain their historic significance and relation to the node. In Walasgala as well, the Bo tree and the temple should be preserved for a strong image of the node. In the case of Wanduramba, the bus station becomes the central place, but residents are in the view that market can be brought back to the vicinity of the bus station to generate a more cohesive center and a strong image. This would also be helpful in generating a strong enclosure to the town (by having shops making an edge), that would in turn improve the imageability of the node. Here too, the Bo-tree shrine and the nearby temples must be given needed attention and should be incorporated to the preservation or development activity.

When considering the linear towns, the entry points, the central space, and the main arterial road (main street) as a spine become the vital elements to be preserved or developed. A strong edge crated by the shops that runs along the main street would strengthen the image. The central node should be around the bus station as discussed so far. The market, railway station, police station or other governmental institutions may be located around it to further strengthen the imageability and orientation through the town. In Akuressa town, there seems to be three significant domains, but can be hierarchically arranged. The central bus station and the surroundings (including the police station and post office) should be the main center, and needs more definition in terms of enclosure from shops. The second center is at the Bangama Road intersection (the old center) with the market, Bodhi-tree, the small open space opposite the market, and the old shops around it. This small open space should be assigned a proper use that retains its openness. The old shops add much character through their noticeable architectural features such as tiled roofs, colors, other details etc.
These can be preserved to keep this historic presence at this node. The third domain is the Tibbotuwawa Junction across the river. Presently the central ground of the junction is filled with temporary structures, which may be cleared to have a proper visual appeal to the node. The sense of history in this node's buildings should be preserved to retain its distinctive image. The old bridge and the Godapitiya Temple evoke meanings and images for residents thus need preservation care. The tea, rubber, cinnamon cultivation in Akuressa also facilitates the imageability of the town.

However, the rule of bus station being the center of the town would not apply to the Imaduwa town. Here, the bus station and the market are located at one end of the town (entry) and the busiest center is the Imaduwa Junction where four roads meet. For residents of Imaduwa, this junction was the hub of the town: for the visitors, it was the most memorable place of the town. Thus, preservation of the setting around the Imaduwa Junction is needed: the line of shops with traditional architectural features such as tiled-gable ended roofs, low-scale etc strengthens the historic presence and the strong enclosure needed. Since the geographical restrictions (town runs at a foot of a mountain) the town could grow along the Galle road towards the Paragoda Temple. Thus, the bus station and the market can be developed into another possible center. This would allow the future growth towards that end rather than demanding the change of the settings around the Imaduwa Junction. In contrast to Akuressa and Imaduwa, Kurundugaha-Hethekma town does not have a specific center, as there are no farmers' market or a central bus station. Thus both visitors and residents mention the clock tower as an important landmark upon which towns identity rests. Residents tend to draw the area around the clock tower as a domain rather than considering it is a segment of the street. Visitors tend to identify the bus stops in the town in the absence of a central bus station. One reason for this not having a bus station is that the town is not a higher order service center for the other towns in the region. It just lies on the road that connects the two top order towns in the region, i.e. Ambalangoda and Elpitiya. Thus it would not be helpful to have a new bus station in the town, as it does not serve any purpose. Rather, the spacious street segment around the clock tower can be developed into a central space where the main bus stops along the road and some important commercial activities are. The near by temple could add much life into this center as well, as it is presently visually obscured: visitors did not identify it at all, although residents considered it as vital to town's identity. Thus this area will be a central space as well as a strong entry point to the town. Some of the old 
shop buildings around this center are worth preserving due to their architectural merit.

In the case of Linear-system towns, there are usually several centers, i.e. bus station and railway station (usually the new centers), market and the old core of the town etc. Thus, there is the need to preserve these centers and, most critical is the connections between these centers. In this type of towns, the bus station and the surrounding area is a later development, which has pulled out much of the life of the old center of the town - usually comprising the market and other shops. Thus preservation of the old center needs revitalization of its economic and social life. A better method would be to connect the new center to the old center by having visual and physical access (spatial) with some suitable commercial activities (uses) along this connection. In Ambalangoda, the Station Road and the commercial activities along it amply connect the old center to the new center. However, the dilapidated condition of the old market needs new life along with the other shops on the old Galle road to have a better use of this arrangement. Bringing the farmers' market into this old node and preserving some of the historic shophouses around the place are required. In Weligama too, this type of connection is needed. The bus station area is connected to the old Weligama Junction by the new Station Road, but the lack of proper visual connection and lack of intensive activities along the road do not provide the desired results. Some residents have mentioned about developing/preserving the tree grove opposite the bus station as a gathering place. This setting can also be used to connect the new center to the old center as this grove lies between the two. Moreover, both in Ambalangoda and Weligama the bus station and the railway station physically close to each other, and hence provide the opportunity to develop a large single domain including both transportation foci. For both these towns, the entry points are important. Thus preservation or proper development of Kumbalgama area (for Weligama) and roundabout and Bridge (for Ambalangoda) is necessary. Again, temples and schools in the town/village are central to the residents' image of these two towns, thus those needs reinforcement in preservation/development activity. Although both these towns have a stock of historic shops, shop-houses, and houses, residents did not mention they as significant to the towns' identities. But due to their historic and architectural merit, these buildings need preservation and proper reintegration into the towns' contemporary life. For Ambalangoda, the masks industry, the Rest Hose, the Hindu Shrine (Modara Devalaya) generate a strong identity, thus they require strengthening and restoration. In Weligama, the Kustharajagala and the Agrabodhi Temple can be incorporated into a one domain and a new religious center can be established. Attention should also be given to the improvement of the beach at the entrance to Weligama as a public recreation space. In the case of the Devinuvara town, the dominant presence (both physical and symbolic) of the main shrine complex would continue to govern the town's growth and the image. Thus preservation of the shrine, shrine complex, and its related structures such as Simhasana and areas is important and should be given adequate attention in any development activity. Its visual prominence should not be obscured with other medium/high rise structures etc. As residents conceptualized, the developments may radiate along the street keeping the main complex the focus of the town. However, a strong urban edge is desired to strengthen the imageability of the town while maintaining a festive character. The Banyan Tree also scems important for both residents and visitors as a prominent landmark.

It should be mentioned here that any preservation activity should take into account the identity, structure, and the meanings associated with each town. The preservation or restoration of landmarks (points) would nol generate the desired results without understanding their relationship to other points, domains, paths, and to the different meanings and associations the town possesses. Thus, the preservation has to deal with the whole fabric of the town, including physical, cultural, and economic aspects.

\section{Future Research Directions}

Although the present research was able to identify the core-characteristics of towns' identities, there are some issues that needs further refinement. It is a difficult issue to identify how exactly people conceptualize the town and its different settings just by looking at their sketch-maps. First it is difficult to identify how their internal mental images exactly look like. Second people make many distortions while drawing and use different annotation techniques in producing these maps. These differences can be due to their age, sex, education, familiarity, drawing skill etc. One method to check the veridicality of the sketch-map and the internal mental map would be to conduct in-depth interviews asking further clarifications for what they drew on their sketch-maps. Participation of the Architecture Students as visitors also raises some validity questions to the findings. Since they possess a specific cognitive style different from that of the residents due to their educational background, they naturally tend to conceptualize the spaces different than ordinary people. 
Thus, research needs participation of ordinary people as visitors, in order to generate a greater external validity to the study. Another study would be analyzing how people give verbal directions to navigate through towns. In such occasions they will tend to select proper elements that are truly important to the orientation and way-finding within the towns, and also would display the nature of the cognitive styles people possess. This would help to supplement the findings of this study. Although these towns have many historic buildings in forms of houses and shops that are worth preserving, people did not mention them as vital to towns' identities. This question should be further studied as to see why they excluded those and how they cognize those buildings.

\section{REFERFNCES}

Abu-Ghazzeh, Tawfiq M. (1998). The Future of Jeddah-Al Qademah: Conservation or Redevelopment-Saudi Arabia. Journal of Architectural and Planning Research. 15(3). 225242.

Briggs, Ronald (1976). Methodologies for the Measurement of Cognitive Distance. In Gary T. Moore \& Reginald G. Golledge. (eds.).

Environmental Knowing:Theories, Research, and Methods. Stroudsburg, Pennsylvania: Dowden, Hutchinson, \& Ross, Inc. 325-334.

Del Rio, Vicente (1997). Restructuring Inner-city Areas in Rio de Janeiro: Urban Design for a Pluralistic Downtown: Journal of Architectural and Planning Research. 14(1).20-34.

Evans, G.W., C. Smith, \& K. Pezdek.(1982). Cognitive maps and urban form. Journal of the American Planning Association. 48: 232-244.

Golledge, Reginald G. (1976). Methods and Methodological Issues in Environmental Cognition Research. In Gary T. Moore \&

Reginald G. Golledge. (eds.). Environmental Knowing: Theories. Research. and Methods. Stroudsburg, Pennsylvania: Dowden, Hutchinson, \& Ross, Inc. 300-313.

Kaplan, Stephen (1976) Adaptation, Structure, and Knowledge. In Gary T. Moore \& Reginald G. Golledge. (eds.). Environmental Knowing: Theories, Research, and Methods. Stroudsburg, Pennsylvania: Dowden, Hutchinson, \& Ross, Inc. 32-48.

Lynch, K. (1960). The Image of the City. Cambridge, MA: MIT Press.
Penfold, George E.(ed.)(1988) Options for Herilage Conservation in the Town of Ingersoll. Ontario, Canada. University of Guelph, Canada.

Rapoport, Amos (1976), Environmental Cognition in Crosscultural Perspective. In Gary T. Moore \& Reginald G. Golledge. (eds.)Environmental Knowing: Theories. Research, and Methods. Stroudsburg, Pennsylvania: Dowden, Hutchinson, \& Ross, Inc. 220-234.

Rapoport, Amos (1978). Culture and the Subjective Effects of Stress. Urban Ecology. Vol.3: 241-261.

Rapoport, Amos (1977), Human Aspects of Urban Form: Towards a man-Environment Approach to Urban Form and Design, Oxford: Pergamon Press Lid.

Rapoport, Amos (1983), Development, Culture Change, and Supportive Design, Habitat Intemational, 7(5/6): 249-268.

Rapoport, Amos (1988), Levels of Meaning in the built environment. In F Poyatos (ed.) Cross Cultural Perspectives in Non-verbal communication, Toronto: Hogrefe.

Sell, James L. \& Ervin H. Zube (1986). Perception of and Response to Environmental. Change Journal of Architectural and Planning Research. 3(1).33-54

-

Senanayake, R.D. (1997). Unpublished B.Sc (BE) Dissertation. University of Moratuwa, Sri Lanka.

Silva, Kapila Dharmasena (1999a) Preserving Historic Uiban Districts: Issues of Culture Change. Stress, and Culturesupportiveness. Unpublished $\mathrm{PhD}$ Term paper. University of Wisconsin-Milwaukee.

Silva, Kapila Dharmasena (1999b) Residents' Cognition of Urban Form: A Conceptual Framework for Analyzing Cognitive Maps and Identifying Urban Design Implications. Unpublished PhD Term Paper. University of WisconsinMilwaukee.

Sowa, Kazimierz Z. (1994). The Value of Krakow's Cultural Space and its Renewal Problems, Journal of Architectural and Planning Research. 11(1). 34-41.

Kapila Dharmasena Silva is a Lecturer at the Department of Architecture, University of Moratuwa. Now reading for a PHD at the university of Wisconsin Milwaukee -USA This paper is an extensively summarized version of a research project funded by the University of Moratuwa. The author wishes to thank the Senate Research Committee, the faculty and the students of the Department of Architecture, University of Moratuwa, and the residents of the towns who participated in the research. 